\title{
TITLE:
}

\section{Community-wide impact of an exotic aphid on introduced tall goldenrod}

$\operatorname{AUTHOR}(\mathrm{S}):$

ANDO, YOSHINO; UTSUMI, SHUNSUKE; OHGUSHI, TAKAYUKI

\section{CITATION:}

ANDO, YOSHINO ...[et al]. Community-wide impact of an exotic aphid on introduced tall goldenrod. Ecological Entomology 2011, 36(5): 643653

\section{ISSUE DATE:}

2011-02-02

URL:

http://hdl.handle.net/2433/197184

\section{RIGHT:}

This is the peer reviewed version of the following article: ANDO, Y., UTSUMI, S. and OHGUSHI, T. (2011), Communitywide impact of an exotic aphid on introduced tall goldenrod. Ecological Entomology, 36: 643-653, which has been published in final form at http://dx.doi.org/10.1111/j.1365-2311.2011.01303.x; This is not the published version. Please cite only the published version; この論文は出版社版でありません。引用の際には出版社版をご確認ご利用ください。 
Title: Community-wide impact of an exotic aphid on introduced tall goldenrod 5

6 Running head: Community-wide impact of exotic aphids

7

8 Authors: Yoshino Ando, Shunsuke Utsumi, and Takayuki Ohgushi

9

10

Corresponding author: Yoshino Ando

19

20 Address: Center for Ecological Research, Kyoto University

21 509-3, 2-chome, Hiranocho, Otsu, Shiga 520-2113, Japan

22 E-mail: ando@ecology.kyoto-u.ac.jp

23 Tel: +81-77-549-8213

24 Fax: +81-77-549-8201 
Ando et al. $\quad 2$

1 Abstract.

2 1. The aphid Uroleucon nigrotuberculatum (Homoptera: Aphididae), which is

3 specialized to the tall goldenrod, Solidago altissima, in its native range, has become a dominant species on the introduced tall goldenrod in Japan. We examined how this exotic aphid influenced arthropod communities on the introduced tall goldenrod in aphid-present (spring) and aphid-absent (autumn) seasons, using an aphid removal experiment.

2. In spring, aphid presence increased ant abundance because aphid honeydew attracted foraging ant workers. We found a significant negative correlation between numbers of ants and herbivorous insects other than aphids on the aphid-exposed plants, but no significant correlation was detected on the aphid-free plants. Thus, the aphid presence was likely to decrease the abundance of co-occurring herbivorous insects through removal behavior of the aphid-tending ants. There were no significant differences in plant traits between the aphid-exposed and aphid-free plants.

3. In autumn, the numbers of lateral shoots and leaves, and the leaf nitrogen content were increased in response to the aphid infestation in spring. Because of the improvement of plant traits by aphid feeding, the abundance of leaf chewers increased on aphid-exposed plants. In contrast, the abundance of sap feeders decreased on the aphid-exposed plants. In particular, the dominant scale insect among sap feeders, Parasaissetia nigra (Homoptera: Coccidae), decreased, followed by a decrease in the abundance of ants attending P. nigra. Thus, aphid feeding may have attenuated the negative impacts of the tending ants on leaf chewers.

4. Aphid presence did not change herbivore species richness but changed the relative density of dominant herbivores, resulting in community-wide effects 
Ando et al. $\quad 3$

1

2

3

4

5

6

$7 \quad$ Key words.

8 aphid-ant interaction $\cdot$ community-wide impact $\cdot$ exotic insect $\cdot$ introduced plant $\cdot$

9 invasion - plant-mediated indirect effect - Solidago altissima - tall goldenrod .

10 Uroleucon nigrotuberculatum 
1

2

3

\section{Introduction}

Ando et al. 4

It is well accepted that introduced plants lack interactions with herbivores, mutualists, and competitors associated with their original ranges, but can gain novel interactions with native species in new habitats (Schiffman 1994; Mitchell et al. 2006). Moreover, the establishment of an introduced plant is often followed by invasion of exotic herbivorous insects that are specialized to the plant in its original region (Robinson, 1980; Memmott et al., 2000; Hierro et al., 2005; Ando \& Ohgushi, 2008).

These exotic insects may affect arthropod communities on introduced plants by adding new interactions or modifying existing interactions, such as interspecific competition for shared resources (Moulton \& Pimm, 1983; Louda et al., 1997; Simberloff \& Von Holle, 1999), ant-mediated indirect interactions (Thum et al., 1997), or plant-mediated indirect interactions (Louda et al., 1997; Louda \& Arnett, 2000). Studying these relationships among introduced plants, exotic and native insects is necessary to answer the questions of how direct and indirect insect-plant interactions are newly formed on novel plants (Sax et al., 2007). Specifically, investigation of indirect effects induced by exotic herbivorous insects at the community level is required to understand the impacts of introduced species on the assemblage of native organisms (Howarth, 1991; Callaway et al., 1999; Louda \& Arnett, 2000). To our knowledge, no studies have examined how exotic herbivorous insects affect the organization of the arthropod community in terms of overall density, species richness, and community composition on introduced plants. This is because most of the studies examining relationships between introduced plants and exotic herbivorous insects have focused on the colonization success of such insects as biological control agents for introduced plants (Crawley, 1989; McClay, 1995; Wajnberg et al., 2001).

Indirect interactions caused by herbivore-induced changes in plants occur frequently among temporally- and spatially-separated, and taxonomically-distinct 
Ando et al. 5

1 species, resulting in community-wide impacts (Van Zandt \& Agrawal, 2004; Ohgushi,

2 2005; Utsumi \& Ohgushi, 2009; Utsumi et al., 2009; Poelman et al., 2010). In this

3 context, aphid colonization can alter host plant traits, such as plant growth, soluble

4 nitrogen content, amino acid and secondary compound concentrations, and resource

5 allocation to roots, shoots, and seeds (Moran \& Whitham, 1990; Waltz \& Whitham,

6 1997; Petersen \& Sandström, 2001; Wimp \& Whitham, 2007). These changes in host

7 plant traits caused by aphid attack can in turn alter arthropod communities. For example,

8 Waltz \& Whitham (1997) demonstrated that leaf-galling aphids increased the abundance

9 and species richness of arthropods by improving the quality of juvenile cottonwood ramets. This implies that aphids can affect arthropod communities indirectly through

11 changes in plant quality.

Interactions between ants and honeydew-producing aphids are common and widespread in arthropod food webs (Kaplan \& Eubanks, 2005). Ant-aphid interactions potentially have community-wide impacts, because the presence of aphids can indirectly alter the density of other herbivorous insects and predators through the removal activities of tending ants (Wimp \& Whitham, 2001, 2007). As honeydew is a renewable food resource, ants tending aphids not only protect aphids from predators and/or parasitoids (Way, 1963; Buckley, 1987), but also exclude potential competitors (Ando \& Ohgushi, 2008). There is increasing evidence that an ant-aphid mutualism has strong indirect impacts on other herbivorous insects and/or their natural enemies through the removal behavior of ants, leading to decreases in the species richness and relative abundance of herbivorous insects (Floate \& Whitham, 1994; Wimp \& Whitham, 2001, 2007). Herbivore species with a pervasive influence on the overall community composition are termed "keystone herbivores" (Hunter, 1992), and their removal can produce a dramatic change in the associated community structure through altering an interaction web involving the host plant and other community members. Therefore, 
Ando et al. 6

1 aphids have the potential to be a keystone herbivore that determines arthropod

2 community structure through both plant- and ant-mediated indirect effects.

3

The tall goldenrod, Solidago altissima, is an herbaceous plant which was introduced to Japan from North America approximately 100 years ago, and has since then spread widely over Japan. The aphid Uroleucon nigrotuberculatum is one of the most dominant species on the tall goldenrod in Japan, and it also came from North America in the early 1990s. This exotic aphid-tall goldenrod system could provide profound insights into how an exotic aphid can affect the arthropod community on introduced plants through both ant-mediated and plant-mediated indirect effects.

In this study, we examined how the exotic aphid affected community structures of co-occurring and temporally separated herbivorous insects and predators, using an aphid-removal experiment. Specifically, we focused on plant traits, species richness and densities of insect herbivores belonging to different feeding guilds and predators of different taxa.

\section{Materials and methods}

Tall goldenrod and aphid

Tall goldenrod, Solidago altissima Linn (Compositae), is a rhizomatous perennial herb that was introduced to Japan from North America approximately 100 years ago (Shimizu, 2003). It has spread widely all over Japan, and become one of the most abundant weeds. It grows in open and disturbed areas, and frequently invades abandoned agricultural fields. In their original habitats, tall goldenrods are attacked by more than 100 herbivorous insect species, including a wide range of feeding guilds, such as leaf-chewers, suckers, miners, and gall-formers (Messina, 1978; Messina \& Root, 1980).

Uroleucon nigrotuberculatum is a stem-feeding aphid (Homoptera) that feeds 
Ando et al. 7

1 exclusively on terminal shoots of $S$. altissima. It was also introduced from North

2 America in the early 1990s (Ôtake, 1999), and more recently it has become very

3 common in Japan. This aphid emerges from overwintered eggs in early March, and

4 disappears by early August. It commonly occurs on S. altissima in North America, and

5 at least seven predators and two parasitoids have been recorded to attack this species

6 (Moran 1986). In contrast, this aphid is almost free from natural enemies in Japan

7 (Ôtake, 1999). Although we observed two ladybirds, Coccinella septempunctata and

8 Harmonia axyridis, and a crab spider, Misumenops tricuspidatus, preying on the aphid,

9 the intensity of predation was negligible in our study area (Y. Ando, personal

10 observation).

Experimental design of aphid exclusion

This study was conducted in a common garden of the Center for Ecological

Research, Kyoto University, in Otsu, Shiga Prefecture, central Japan. To investigate the effects of the aphid colonization on other herbivorous insects and predators, we performed an aphid exclusion experiment in 2001. Eighty seedlings of different clones of tall goldenrods were randomly taken from a 0.75-ha field of the Experimental Forest of Field Science Education and Research Center of Kyoto University in Kyoto $\left(35^{\circ} 04^{\prime} \mathrm{N}, 135^{\circ} 46^{\prime} \mathrm{E}\right.$; altitude $109 \mathrm{~m}$, annual mean temperature $14.6{ }^{\circ} \mathrm{C}$, and mean precipitation $1582 \mathrm{~mm}$ ), and were planted in pots individually in early May, 2001. Two weeks later, all of the potted plants were transplanted into an experimental plot in a 6 $\mathrm{m} \times 16 \mathrm{~m}$ grid in the common garden by burying the bottom half of a pot in the ground, with individual plants being spaced $1.5 \mathrm{~m}$ apart without boundary fences. Aphid-exposed and aphid-free treatments were alternately arranged, and plants of the aphid-exposed treatment were allowed to undergo natural colonization by aphids. We checked all plants every day from mid-May to August, and removed aphids from the 
Ando et al. 8

1 aphid-free plants with forceps when they were found. To confirm whether aphid

2 colonization occurred in the aphid-exposed treatment, we counted aphids weekly

3 throughout the season. We used 40 potted plants for an arthropod community census

4 and the other 40 plants for an experiment to examine the effects of aphids on host plant

5 traits. In both experiments, 20 plants each were assigned to the aphid-free treatment, and

6 the remaining 20 plants to the aphid-exposed treatment.

7

8 Effects of aphid colonization on herbivore and predator communities

To examine how the aphid affected herbivore and predator communities in the common garden, we conducted censuses three times a week from mid-May to late October 2001. The number of species and abundance of each arthropod species were recorded in the aphid-free and aphid-exposed plants. As the aphid colonization occurs from mid-May to early August and none of the herbivorous insect species except one found in the aphid-present season appeared in the aphid-absent season (see Appendix 1), we analyzed the aphid effects separately in "early season” (aphid-present season, i.e., mid-May to August) and "late season" (aphid-absent season, i.e., September to late October). The census data for each arthropod species were averaged for the early and late season, respectively, and then we calculated the overall abundance and species richness of the herbivore and predator communities on each plant. The Wilcoxon signed rank test was used to compare these community properties between the aphid-free and aphid-exposed plants. Also, we compared the abundance of each feeding guild of herbivorous insects and predator taxa between the aphid-free and aphid-exposed plants. Herbivorous insects found on each plant were classified into two feeding guilds, namely, leaf chewers (caterpillars, grasshoppers, chrysomelid beetles, and scarab beetles) and sap feeders (aphids, leafhoppers, stinkbugs, scales, and spittlebugs). We excluded leaf miners from this analysis, because it was difficult to determine whether individual leaf 
Ando et al. 9

1 miners were alive. Predators were categorized in terms of taxa: spiders, ants, and others

2 (Cantharidae, Coccinellidae, and Reduviidae, Appendix 2). The Wilcoxon signed rank

3 test was used to compare overall abundances of herbivore feeding guilds and predator

4 taxa on the aphid-free and aphid-exposed plants. To examine the numerical relationships

5 among aphids, ants, and co-occurring herbivores, we calculated Pearson's correlation

6 coefficients between numbers of aphids and ants, between numbers of ants and leaf

7 chewers, and between numbers of ants and sap feeders.

8 To examine whether arthropod communities differed between the treatments,

9 we used nonmetric multidimensional scaling analysis (NMDS) with the Bray-Curtis dissimilarity coefficient. This is a robust technique which represents samples as points in low-dimensional space (usually two dimensions) such that the relative distances apart of all points are in the same rank order as the relative dissimilarities of the samples

13 (Minchin, 1987). Points that are close together represent samples that are very similar in community composition, based on number of species and relative abundance of each species. For this analysis, the number of each herbivore and predator species used in the analysis was averaged for the early and late seasons. Uroleucon nigrotuberculatum on the aphid-exposed plants was excluded from the analysis. Individual numbers of each species were $\log (n+1)$-transformed and standardized by variance prior to calculating the coefficient.

An optimal NMDS solution was obtained by minimizing the stress value as described in Clarke \& Gorley (2001). The stress value (goodness-of-fit of the NMDS plot) is an index to indicate how faithfully the high-dimensional relationships among samples are represented in a two-dimensional ordination plot. The stress value, which decreases as the rank-order agreement between distances and dissimilarities improves, was calculated as described by Kruskal (1964). When stress values are $\leq 0.1$, the NMDS plot is considered to be an acceptable representation (Clarke, 1993). The relationships 
Ando et al. 10

1 among samples were represented in a plot of the first two dimensions of the NMDS

2 solution. Then, differences in community compositions of predators and herbivores

3 between the aphid-exposed and aphid-free plants were determined by the $\mathrm{R}$ value in an

4 analysis of similarity (ANOSIM; Clarke, 1993). This analysis uses non-parametric

5 permutation/randomization methods with a dissimilarity matrix (Clarke, 1993). In

6 addition, we used similarity percentages (SIMPER) to identify which arthropod species

7 primarily accounted for the differences in herbivore and predator communities between

8 the two plants. SIMPER is used to examine the contribution of each species or group to

9 the average Bray-Curtis dissimilarity between samples (Clarke, 1993). We conducted

NMDS, ANOSIM, and SIMPER analysis using the software program PRIMER-5

11 version 5.2.9 (Plymouth Marine Laboratory, Plymouth, UK).

13 Effects of aphid colonization on plant traits

Because aphid infection induces subsequent branching, thereby enhancing new leaf production late in the season (Ando \& Ohgushi, 2008), it has the potential to affect late-emerging arthropods on the tall goldenrod through the enhancement of plant regrowth.

To examine how plant traits differed between treatments in the common garden in the early and late seasons, we prepared aphid-exposed plants ( $\mathrm{n}=20)$ and aphid-free plants $(n=20)$ in the common garden, as described in the experimental design above. After the number of newly emerged lateral shoots and leaves were counted, ten leaves were randomly taken from ten each of aphid-exposed plants and aphid-free plants for measurement of foliar nitrogen and water contents in mid-July and in early September 2001 just before the emergence of late season herbivores, the number of shoots and leaves of the remaining ten each of aphid-exposed plants and aphid-free plants were counted, and then ten leaves were randomly collected from each plant to 
Ando et al. 11

1 measure foliar nitrogen and water contents. Individual leaves were weighed in the

2 laboratory and oven-dried at $60^{\circ} \mathrm{C}$ for $48 \mathrm{~h}$ to calculate water content. After the dried

3 leaves were powdered, nitrogen content was measured using an elemental analyzer

4 (Macro Corder JM1000CN, J-Science, Kyoto, Japan). The Wilcoxon signed rank test

$5 \quad$ was used to compare these traits between the aphid-exposed and aphid-free plants.

\section{$7 \quad$ Results}

8 Effects of aphids on overall density and species richness

9 We recorded a total of 1701 individuals in 29 species as herbivores (Appendix 1) and a total of 1379 individuals in 62 species as predators (Appendix 2). All of the aphid-exposed plants were colonized by aphids throughout the early season (Mean of aphid abundance \pm SE; $9.01 \pm 0.39$ ). We found no aphids on the aphid-free plants throughout the season. The aphid-exposed plants had significantly lower overall herbivore density, i.e., number per plant, than the aphid-free plants in both the early and late seasons (Wilcoxon signed rank test: $Z=82.32, P<0.001$ for early season; $Z=$ 20.02, $P<0.001$ for late season, Fig. 1). Although herbivore species richness in the early season showed a tendency to be lower on the aphid-exposed plants than on the aphid-free plants, the difference was not statistically significant $(Z=3.12, P=0.07$ for early season; $Z=1.65, P=0.13$ for late season). Of 29 herbivorous insect species, $86 \%$ were found on both the aphid-exposed and aphid-free plants (Appendix 1). Overall predator density on the aphid-exposed plants was significantly higher in the early season $(Z=52.36, P<0.001)$ but was lower in the late season $(Z=47.78, P<0.001)$ than that on the aphid-free plants. Also, there were marginally significant differences in species richness in both seasons $(Z=3.11, P=0.06$ for early season; $Z=3.28, P=0.06$ for late season, Fig. 1). Predator species richness on the aphid-exposed plants in both 
Ando et al. 12

1 seasons tended to be lower than that on the aphid-free plants. Of 62 predator species,

$290 \%$ were found on both the aphid-exposed and aphid-free plants (Appendix 2).

3

4 Effects of aphids on community composition

NMDS analysis of the dissimilarity of arthropod community composition revealed that both herbivore and predator communities on the aphid-exposed plants were clearly distinct from those on the aphid-free plants in both seasons (ANOSIM: herbivore: $R=0.60, P<0.001$ for early season; $R=0.82, P<0.001$ for late season; predator: $R=0.66, P<0.001$ for early season; $\mathrm{n}=20, R=0.22, P<0.001$ for late season, Fig. 2). SIMPER analysis indicated that the leafhopper Nephotettix cincticeps Uhler and the moth caterpillar Ascotis selenaria Butler accounted for $46 \%$ and $35 \%$ of the dissimilarity of herbivore communities between the aphid treatments in the early season. The leafhopper constituted $66 \%$ and $89 \%$ of the overall sap feeder abundance on the aphid-exposed plants and aphid-free plants, respectively. Also, the moth caterpillar constituted $78 \%$ and $86 \%$ of the overall leaf chewer abundance, respectively. In the late season, the scale insect Parasaissetia nigra Nietner and the grasshopper Atractomorpha lata Motschulsky accounted for $62 \%$ and $29 \%$ of the dissimilarity of herbivore communities between treatments. The scale insect constituted $79 \%$ and $91 \%$ of the overall sap feeder abundance on the aphid-exposed plants and aphid-free plants, respectively. Also, the grasshopper constituted 85\% and $41 \%$ of the overall leaf chewer abundance on the aphid-exposed plants and aphid-free plants, respectively. The ant Formica japonica accounted for $95 \%$ and $92 \%$ of the dissimilarities of predator communities in the early season and the late season, respectively. Regarding the overall ant abundance on the aphid-exposed and aphid-free plants, the ant constituted $98 \%$ and $74 \%$ in the early season, and $91 \%$ and $93 \%$ in the late season, respectively. These results suggest that the differences 
Ando et al. 13

1

between arthropod communities with and without aphids were due to the differences in relative abundances of the dominant herbivore species and ants.

Effects of aphids on densities of herbivore guilds and predator taxon

In the early season, the densities of leaf chewers and sap feeders were significantly lower on the aphid-exposed plants than on the aphid-free plants (Wilcoxon signed rank test: $Z=24.37, P<0.001$ for leaf chewers; $Z=38.66, P<0.001$ for sap feeders, Fig. 3). In the late season, there was significantly higher density of leaf chewers but lower density of sap feeders on the aphid-exposed plants than on the aphid-free plants $(Z=32.12, P<0.001$ for leaf chewers; $Z=39.65, P<0.001$ for sap feeders).

Regarding arthropod predators, ant density was significantly higher in the early season but was lower in the late season on the aphid-exposed plants than on the aphid-free plants $(Z=36.94, P<0.001$ for early season; $Z=62.34, P<0.001$ for late season, Fig. 3). Neither spiders nor other predators differed significantly between the two treatments in either season (early season: $Z=1.12, P=0.07$ for spiders; $Z=0.84, P$ $=0.13$ for others; late season: $Z=0.58, P=0.64$ for spiders; $Z=0.21, P=0.84$ for others).

The number of ants was positively correlated with the number of aphids on the aphid-exposed plants (Pearson correlation coefficient: $r=0.82, P<0.001, \mathrm{n}=20$; two-tailed test). The numbers of leaf chewers and sap feeders were negatively correlated with the number of ants on the aphid-exposed plants (ants vs. leaf chewers: $\mathrm{n}=20, r=$ -0.75, $P<0.001$; ants vs. sap feeders: $\mathrm{n}=20, r=-0.77, P<0.001)$. In contrast, no significant correlations were found between the numbers of herbivorous insects and ants on the aphid-free plants (ants vs. leaf chewers: $\mathrm{n}=20, r=-0.41, P=0.07$; ants vs. sap feeders: $\mathrm{n}=20, r=-0.53, P=0.07)$. 
Ando et al. 14

1 Effects of aphids on plant traits

2

3

4

5

6

7

8

Aphid infestation enhanced the production of newly emerged lateral shoots and leaves. The new leaf flush increased the foliar nitrogen content by $150 \%$ in the late season, but not in the early season (Table 1). There was no significant difference in the foliar water content between the aphid treatments. The aphid-exposed plants had about three times more leaves in the late season, compared to the aphid-free plants. Most of the increase of leaves in aphid-exposed plants was due to secondary growth in response to the early aphid colonization. These results suggest that the aphid colonization not only enhanced the production of lateral shoots and leaves, but also improved the quality of leaves that emerged in the late season.

\section{Discussion}

Effects of aphids on the co-occurring arthropod community

This study clearly demonstrated the community consequences of aphid-ant interaction as a driver structuring arthropod communities. In the early season, the ant density was twelve times higher on the aphid-exposed plants than on the aphid-free plants, as a result of the provision of aphid honeydew to ant workers. Aphid-tending ants protect aphids from their natural enemies or competitors (Sloggett \& Majerus, 2000; Stadler \& Dixon, 2005). Although there are many studies on aphid-ant mutualistic interactions (Stadler \& Dixon, 2005), to date the community consequences of their interactions have received little attention (but see Wimp \& Whitham, 2001; Styrsky \& Eubanks, 2007; Mooney \& Agrawal, 2008; Sanders \& van Veen 2010). Our study showed that ants had a negative impact on other herbivores on the aphid-exposed plants, because the ants frequently removed herbivorous insects. In particular, the aphid presence decreased the dominant sap feeder, $N$. cincticeps, and the dominant leaf chewer A. selenaria, resulting in significant alterations in the herbivore community 
Ando et al. 15

1 structure.

2

3

4

5

6

The aphid may have affected early-season insect herbivores through exploitative competition or induced plant responses that changed plant quality. Co-occurring phloem feeders often compete for assimilates in the phloem vessels of host plants (Denno \& Kaplan, 2007). Inbar et al. (1995) reported that aphids increased the mortality of co-occurring sap feeders via diversion of assimilates. In addition, aphids can change leaf nitrogen, plant growth, and resource allocation to roots, shoots, and seeds (Moran \& Whitham, 1990; Petersen \& Sandström, 2001), resulting in decreased food availability to leaf chewers or sap feeders. However, it is not likely that such effects on leaf chewers occurred in this study, because aphid colonization changed neither leaf nitrogen nor water content, nor production of lateral shoots or leaves of $S$. altissima.

The aphid presence also significantly increased predator abundance due to an increase in aphid-tending ants, although spiders and other predators were unaffected. On the other hand, predator species richness was marginally lower on the aphid-exposed plants, because three spider species found on aphid-free plants were lacking (see Appendix 2). This negative impact of ants on other predators is in accord with the finding of an aphid removal experiment on cottonwood trees (Wimp \& Whitham 2001), showing that species richness of generalist predators was two times greater when aphids and associated ants were absent than when they were present. Hence, the community composition of predators differed significantly depending on whether the aphids were present or absent.

Effects of aphids on the temporally separated arthropod community

The aphid colonization in the early season impacted the herbivore community in the late season when the aphid was no longer present. Aphids influenced the 
Ando et al. 16

1 late-season herbivore community composition by decreasing the sap feeder P. nigra and

2 increasing the leaf chewer $A$. lata, both of which contributed robustly to the difference

3 in the community composition of herbivorous insects.

The aphid colonization in the early season influenced temporally separated

5 herbivorous insects in the late season by alteration of food quality and quantity,

6 depending on the feeding guild. Ando \& Ohgushi (2008) showed that the aphid

7 infestation in the early season did not affect plant traits in terms of secondary growth or

8 foliar nitrogen, but rather increased the number of newly emerged lateral shoots and

9 leaves and the foliar nitrogen in the late season. This trend was also supported by the present study. In late August, leaf flush continuously occurred in the aphid-exposed

11 plants, although it rarely occurred in the aphid-free plants. This increase in newly

12 flushed leaves in aphid-exposed plants resulted in an increase in leaf nitrogen level,

13 which improved food availability to the grasshopper A. lata (Ando \& Ohgushi, 2008).

14 Such a trait change in host plants due to regrowth following early-season herbivory often has positive effects on late-emerging herbivorous insects because of increased resource quality and/or quantity (Mopper et al., 1991; Masters et al., 2001; Ohgushi, 2005).

In contrast, aphid infestation often decreases the abundance of subsequent sap feeders by reducing the nutritional quality of the sap of host plants, inducing amino acid alterations or increasing secondary compounds (Petersen \& Sandström, 2001; Denno \& Kaplan, 2007). Sap feeders would be strongly affected by qualitative changes in phloem sap but not by increased leaf production of the aphid-infested plants. Ando \& Ohgushi (2008) showed that population growth and survival of $P$. nigra in autumn were decreased by spring aphid infestation. Moreover, aphids may have increased leaf chewers through a decrease in P. nigra. Since honeydew of the scale insect attracts ants (Williams \& Watson, 1990), a decrease of scale insects on the aphid-exposed plants may 
Ando et al. 17

1 decrease the removal of other herbivores by tending ants. In the present study, ant

2 density was decreased by $23 \%$ on aphid-exposed plants. Hence, the presence of aphids

3 in the early season may attenuate the negative impact of the ants attending scale insects on leaf chewers in the late season.

The predator abundance significantly decreased on the plants with

6 early-season aphid infestation because of the decreased number of ants tending scale

7 insects. However, the early-season aphid infestation did not affect the abundance of

8 spiders or other predators. Also, predator species richness was lower on the

9 aphid-exposed plants with low density of ants attending scale insects relative to the aphid-free plants. As a result, the community composition of predators on the aphid-exposed plants with early-season aphid infestation differed significantly from that on the aphid-free plants.

Aphid as a keystone herbivore forming indirect interaction webs communities, and thus lead to community-wide impacts (Wimp \& Whitham, 2001; Styrsky \& Eubanks, 2005). On the other hand, aphid colonization can also significantly affect the performance and/or preference of other herbivorous insects by altering the quality and quantity of host plants (Way \& Cammell, 1970; Waltz \& Whitham, 1997; Petersen \& Sandström, 2001), which may alter the structure of herbivore communities. Our study highlighted that plant-mediated indirect effects of the aphid colonization significantly influenced the community structure of temporally separated herbivorous insects via alteration of not only food quality and quantity, but also the strength of ant-mediated indirect effects. Note that indirect effects of aphids on temporally separated herbivorous insects depend on the feeding modes, resulting in a decrease in sap feeders but an increase in leaf chewers. This suggests that aphid infestation can have 
Ando et al. 18

1 strong and different impacts on herbivorous insects through ant-aphid mutualism in the

2 early season and can cause changes in host plants in the late season, extending to

3 community-level consequences. Thus, aphids can act as a keystone herbivore in

4 determining arthropod community structure through both ant-mediated and plant

5 trait-mediated indirect effects. Future studies will be needed to obtain more information

6 on the relative importance of plant-mediated indirect effects, ant-mediated indirect

7 effects, and their interactions in community organization on plants, to achieve a better

8 understanding of herbivore-induced indirect effects on ecological communities in

9 nature.

Several studies on biological weed control argued that exotic herbivorous insects employed as control agents for introduced plants affected not only the target plants but also native organisms in a novel habitat through direct and/or indirect interactions (Howarth, 1991; Callaway et al., 1999; Louda \& Arnett, 2000). In this context, this study revealed that the exotic aphid $U$. nigrotuberculatum played a key role in structuring the arthropod community on introduced tall goldenrods in both the early and late season. Investigating the relative importance of exotic herbivorous insects in interaction webs on introduced plants is a fruitful challenge for clarifying how exotic herbivorous insects that invade following the establishment of introduced plants have community-level consequences in invasion processes.

\section{Acknowledgements}

We thank T. P. Craig, J. R. Etterson, and D. H. Hembry for valuable comments on the manuscript, A. Lester for valuable supports, and E. Nakajima for editing the English of the manuscript. This study was partly supported by the Ministry of Education, Culture, Sports, Science and Technology Grant-in-Aid for Scientific 
Ando et al. 19

1 Program (A14) and the Global COE program (A06) to Kyoto University.

2 
Ando et al. 20

1

2

3

4

5

6

7

8

9

\section{References}

Ando, Y. \& Ohgushi, T. (2008) Ant-and plant-mediated indirect effects induced by aphid colonization on herbivorous insects on tall goldenrod. Population Ecology, 50, 181-189.

Buckley, R. (1987) Interactions involving plants, Homoptera, and ants. Annual Review of Ecology and Systematics, 18, 111-135.

Callaway, R.M., DeLuca, T. \& Belliveau, W.M. (1999) Herbivores used for biological control may increase the competitive ability of the noxious weed Centaurea maculosa. Ecology, 80, 1196-1201.

Clarke, K.R. \& Gorley, R.N. (2001) PRIMER v5: user manual/tutorial. Primer-E Ltd.

Clarke, K.R. (1993) Non-parametric multivariate analyses of changes in community structure. Australian Journal of Ecology, 18, 117-143.

Crawley, M.J. (1989) The successes and failures of weed biocontrol using insects. Biocontrol News and Information, 10, 213-223.

Denno, R.F. and Kaplan, I. (2007) Plant-mediated interactions in herbivorous insects: mechanisms, symmetry, and challenging the paradigms of competition past. Ecological communities: plant mediation in indirect interaction webs (ed. by T. Ohgushi, T. P. Craig and P. W. Price), pp. 19-50. Cambridge University Press, Cambridge.

Floate, K.D. \& Whitham, T.G. (1994) Aphid-ant interaction reduces chrysomelid herbivory in a cottonwood hybrid zone. Oecologia, 97, 215-221.

Hierro, J.L., Maron, J.L. \& Callaway, R.M. (2005) A biogeographical approach to plant invasions: the importance of studying exotics in their introduced and native range. Journal of Ecology, 93, 5-15.

Howarth, F.G. (1991) Environmental impacts of classical biological control. Annual Review of Entomology, 36, 485-509. 
Ando et al. 21 plant: the keystone herbivore concept. Effect of Resource Distribution on Plant-animal Interactions (ed. by M. D. Hunter, T. Ohgushi and P. W. Price), pp. 287-325. Academic Press, San Diego.

Inbar, M., Eshel, A. \& Wool, D. (1995) Interspecific competition among phloem-feeding insects mediated by induced host-plant sinks. Ecology, 76, 1506-1515.

Kaplan, I. \& Eubanks, M.D. (2005) Aphids alter the community-wide impact of fire ants. Ecology, 86, 1640-1649.

Kruskal, J.B. (1964) Nonmetric multidimensional scaling: a numerical method. Psychometrika, 29, 115-129.

Louda, S.M., Kendall, D., Connor, J. \& Simberloff, D. (1997) Ecological effects of an insect introduced for the biological control of weeds. Science, 277, 1088-1090.

Louda, S.M. \& Arnett, A.E. (2000) Predicting non-target ecological effects of biological control agents: evidence from Rhinocyllus conicus. Proceedings of the $X$ international symposium on biological control of weeds (ed. by N. R. Spencer), pp. 551-567. Montana State University, Bozeman.

Masters, G.J., Jones, T.H. \& Rogers, M. (2001) Host-plant mediated effects of root herbivory on insect seed predators and their parasitoids. Oecologia, 127, 246-250.

McClay, A.S. (1995) Beyond “before-and-after”: experimental design and evaluation in classical weed biocontrol. Proceedings of the VIII international symposium on biological control of weeds (ed. by E. S. Delfosse and R. R. Scott), pp. 213-219. Lincoln University, Canterbury.

Memmott, J., Fowler, S.V., Paynter, Q., Sheppard, A.W. \& Syrett, P. (2000) The invertebrate fauna on broom, Cytisus scoparius, in two native and two exotic 
habitats. Acta Oecologica, 21, 213-222.

Ando et al. 22

Messina, F. J. (1978) Mirid fauna associated with old-field goldenrods (Solidago: Compositae) in Ithaca, NY. Journal of New York Entomological Society, 86, 137-143.

Messina, F. J., Root, R. B. (1980) Association between leaf beetles and meadow goldenrods (Solidago spp.) in central New York. Annals of the Entomological Society of America, 73, 641-646.

Minchin, P.R. (1987) An evaluation of the relative robustness of techniques for ecological ordination. Vegitatio, 69, 89-107.

Mitchell, C.E., Agrawal, A.A., Bever, J.D., Gilbert, G.S., Hufbauer, R.A., Klironomos, J.N., Maron, J.L., Morris, W.F., Parker, I.M., Power, A.G., Seabloom, E.W., Torchin, M.E., \& Vazquez, D.P. (2006) Biotic interactions and plant invasions. Ecology Letters, 9, 726-740.

Mooney, K.A. \& Agrawal, A.A. (2008) Plant genotype shapes ant-aphid interactions: implications for community structure and indirect plant defense. The American Naturalist, 171, 195-205.

Mopper, S., Maschinski, J., Cobb, N. \& Whitham, T.G. (1991) A new look at habitat structure: consequences of herbivore-modified plant architecture. Habitat structure: the physical arrangement of objects in space (ed. by S. S. Bell, E. D. McCoy and H. R. Mushinsky), pp. 260-280. Chapman and Hall, London.

Moran, N. (1986) Benefits of host plant specificity in Uroleucon (Homoptera: Aphididae). Ecology, 67, 108-115.

Moran, N.A. \& Whitham, T.G. (1990) Interspecific competition between root-feeding and leaf-galling aphids mediated by host-plant resistance. Ecology, 71, 1050-1058.

Moulton, M.P. \& Pimm, S.L. (1983) The introduced hawaiian avifauna: biogeographic evidence for competition. The American Naturalist, 121, 669-690. 
Ando et al. 23

1 Ohgushi, T. (2005) Indirect interaction webs: herbivore-induced effects through trait change in plants. Annual Review of Ecology, Evolution, and Systematics, 36, 81-105.

Ôtake, A. (1999) Analytical study of fundatrix populations of Uroleucon nigrotuberculatum (Olive) (Hemiptera: Aphididae: Aphidinae) on an observation plot of the goldenrod Solidago altissima L. Applied Entomology and Zoology, 34, 435-442.

Petersen, M.K. \& Sandström, J.P. (2001) Outcome of indirect competition between two aphid species mediated by responses in their common host plant. Functional Ecology, 15, 525-534.

Poelman, E.H., van Loon, J.J.A., van Dam, N.M., Vet, L.E.M. \& Dicke, M. (2010) Herbivore-induced plant responses in Brassica oleracea prevail over effects of constitutive resistance and result in enhanced herbivore attack. Ecological Entomology, 35, 240-247.

Robinson, A.G. (1980) A new species of Aphis L. (Homoptera: Aphididae) from nasturtium. Canadian Entomologist, 112, 123-125.

Sanders, D., van Veen, F.J.F. (2010) The impact of an ant-aphid mutualism on the functional composition of the secondary parasitoid community. Ecological Entomology, 35, 704-710.

Sax, D.F., Stachowicz, J.J., Brown, J.H., Bruno, J.F., Dawson, M.N., Gaines, S.D., Grosberg, R.K., Hastings, A., Holt, R.D., Mayfield, M.M., O’Connor, M.L., \& Rice, W.R. (2007) Ecological and evolutionary insights from species invasions. Trends in Ecology and Evolution, 22, 465-471.

Schiffman, P.M. (1994) Promotion of exotic weed establishment by endangered giant kangaroo rats (Dipodomys ingens) in a California grassland. Biodiversity and Conservation, 3, 524-537. 
Ando et al. 24

1 Shimizu, T. (2003) Naturalized plants of Japan. Heibonsha, Tokyo (in Japanese).

2 Simberloff, D. \& Von Holle, B. (1999) Positive interactions of nonindigenous species: invasional meltdown? Biological Invasions, 1, 21-32.

Sloggett, J.J. \& Majerus, M.E.N. (2000) Aphid-mediated coexistence of ladybirds (Coleoptera: Coccinellidae) and the wood ant Formica rufa: seasonal effects, interspecific variability and the evolution of a coccinellid myrmecophile. Oikos, 89, 345-359.

Stadler, B. \& Dixon, A.F.G. (2005) Ecology and evolution of aphid-ant interactions. Annual Review of Ecology, Evolution, and Systematics, 36, 345-372.

Styrsky, J.D. \& Eubanks, M.D. (2007) Ecological consequences of interactions between ants and honeydew-producing insects. Proceedings of the Royal Society B: Biological Sciences, 274, 151.

Thum, R., Paynter, Q., Völkl, W. \& Hoffmann, K.H. Ant-homoptera-phytophage-plant interactions: are ant-tended homoptera good for biological control? Mitteilung Deutschen Gesellschaft für Allgemeine und Angewandte Entomologie, 11, 711-715.

Utsumi, S. \& Ohgushi, T. (2009) Community-wide impacts of herbivore-induced plant regrowth on arthropods in a multi-willow species system. Oikos, 118, 1805-1815.

Utsumi, S., Nakamura, M. \& Ohgushi, T. (2009) Community consequences of herbivore-induced bottom-up trophic cascades: the importance of resource heterogeneity. Journal of Animal Ecology, 78, 953-963.

Van Zandt, P.A. \& Agrawal, A.A. (2004) Community-wide impacts of herbivore-induced plant responses in milkweed (Asclepias syriaca). Ecology, 85, 2616-2629.

Wajnberg, E., Scott, J.K. \& Quimby, P.C. (2001) Evaluating indirect ecological effects of biological controls. CABI publishing, New York. 
1 Waltz, A.M. \& Whitham, T.G. (1997) Plant development affects arthropod communities: opposing impacts of species removal. Ecology, 78, 2133-2144.

Way, M.J. (1963) Mutualism between ants and honeydew-producing homoptera. Annual Review of Entomology, 8, 307-344.

Way, M.J. \& Cammell, M. (1970) Aggregation behavior in relation to food utilization by aphids. Animal populations in relation to their food resources (ed. by A. Watson), pp. 229-247. Blackwell Scientific Publications, Oxford.

Williams, D.J. \& Watson, G.W. (1990) The scale insects of the tropical south pacific region, 3: The soft scales (Coccidae) and other families. CAB International, Wallingford, UK.

Wimp, G.M. \& Whitham, T.G. (2001) Biodiversity consequences of predation and host plant hybridization on an aphid-ant mutualism. Ecology, 82, 440-452.

Wimp, G.M. \& Whitham, T.G. (2007) Host plants mediate ant-aphid mutualisms and their effects on community structure and diversity. Ecological communities: plant mediation in indirect interaction webs (ed. by T. Ohgushi, T. P. Craig and P. W. Price), pp. 275-305. Cambridge Univ. Press, Cambridge. 
Ando et al. 26

1 Table 1. Effects of aphid colonization on traits of aphid-exposed plants and aphid-free

2 plants.

3

\begin{tabular}{|c|c|c|c|c|c|}
\hline \multirow[t]{2}{*}{ Trait } & \multirow[t]{2}{*}{ Season } & \multicolumn{2}{|c|}{ Mean \pm SE } & \multicolumn{2}{|c|}{ Wilcoxon signed rank test } \\
\hline & & Aphid-exposed & Aphid-free & Z & $P$ \\
\hline \multirow[t]{2}{*}{ Number of lateral shoots } & mid-July & 0 & 0 & & \\
\hline & early Sep. & $2.02 \pm 0.63$ & 0 & -6.16 & $<0.001$ \\
\hline \multirow[t]{2}{*}{ Number of leaves } & mid-July & $13.4 \pm 3.13$ & $12.8 \pm 3.09$ & -1.18 & 0.24 \\
\hline & early Sep. & $47.8 \pm 7.72$ & $17.5 \pm 1.43$ & -6.24 & $<0.001$ \\
\hline \multirow[t]{2}{*}{ Nitrogen content (\%DW) } & mid-July & $1.36 \pm 0.14$ & $1.32 \pm 0.18$ & -0.84 & 0.40 \\
\hline & early Sep. & $2.64 \pm 0.27$ & $1.80 \pm 0.23$ & -6.15 & $<0.001$ \\
\hline \multirow[t]{2}{*}{ Water content (\%FW) } & mid-July & $60.0 \pm 2.30$ & $61.4 \pm 3.23$ & -0.51 & 0.61 \\
\hline & early Sep. & $64.7 \pm 1.82$ & $63.8 \pm 2.89$ & -0.12 & 0.23 \\
\hline
\end{tabular}




\section{$1 \quad$ Figure Legends}

Ando et al. 27

2

3 Fig. 1. Overall density (number per plant) and species richness of herbivores and predators on the aphid-exposed and aphid-free plants in the early season (mid-May to August) and late season (September to late October). Data from the aphid-exposed plants do not include U. nigrotuberculatum. Vertical bars indicate means with SE. ${ }^{*} P<0.001$ (Wilcoxon signed rank test).

Fig. 2. Community compositions of herbivores and predators on the aphid-exposed plants $(\bullet)$ and aphid-free plants (०) in the early season (mid-May to August) and late season (September to late October) (herbivore; NMDS stress $=0.12$, ANOSIM: $\mathrm{R}=0.60, P<0.001$ for early season, NMDS stress $=0.11, \mathrm{R}=0.82, P$ $<0.001$ for late season; predator, NMDS stress $=0.20$, ANOSIM: $\mathrm{R}=0.66, P<$ 0.001 for early season, NMDS stress $=0.23, \mathrm{R}=0.22, P<0.001$ for late season). Data from the aphid-exposed plants do not include U. nigrotuberculatum.

Fig. 3. Densities of herbivore guilds (left) and predator taxa (right) on the aphid-exposed and aphid-free plants in the early season (mid-May to August) and late season (September to late October). Data from the aphid-exposed plants do not include $U$. nigrotuberculatum. Vertical bars indicate means with SE. ${ }^{*} P<0.001$ (Wilcoxon signed rank test). 
Ando et al. 28

$1 \quad$ Fig. 1

2

Aphid-exposed

$\square$ Aphid-free
- Aphid-exposed

$\square$ Aphid-free
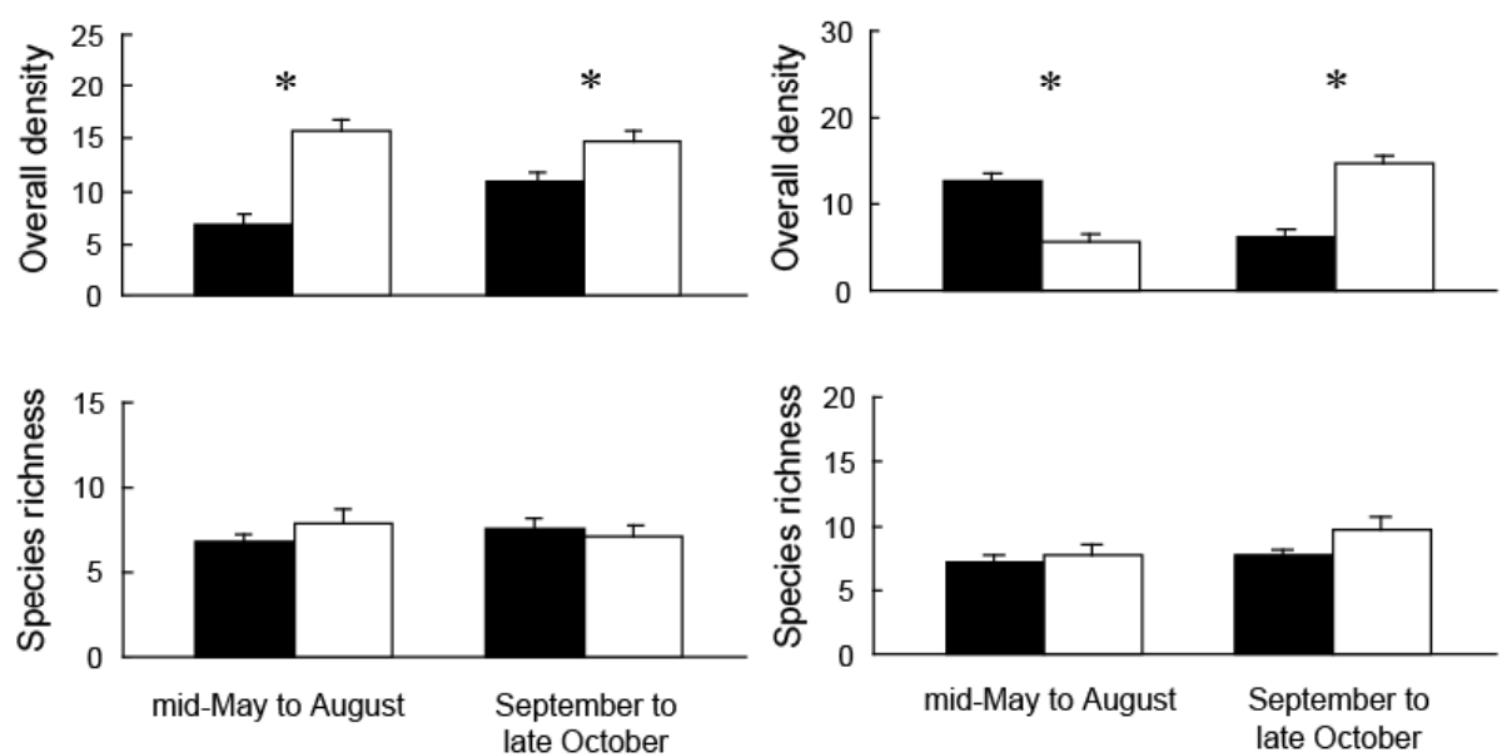

Herbivores

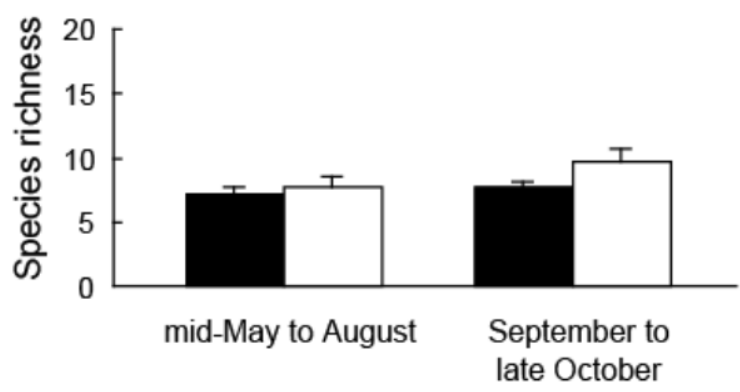

Predators 
$1 \quad$ Fig. 2

2

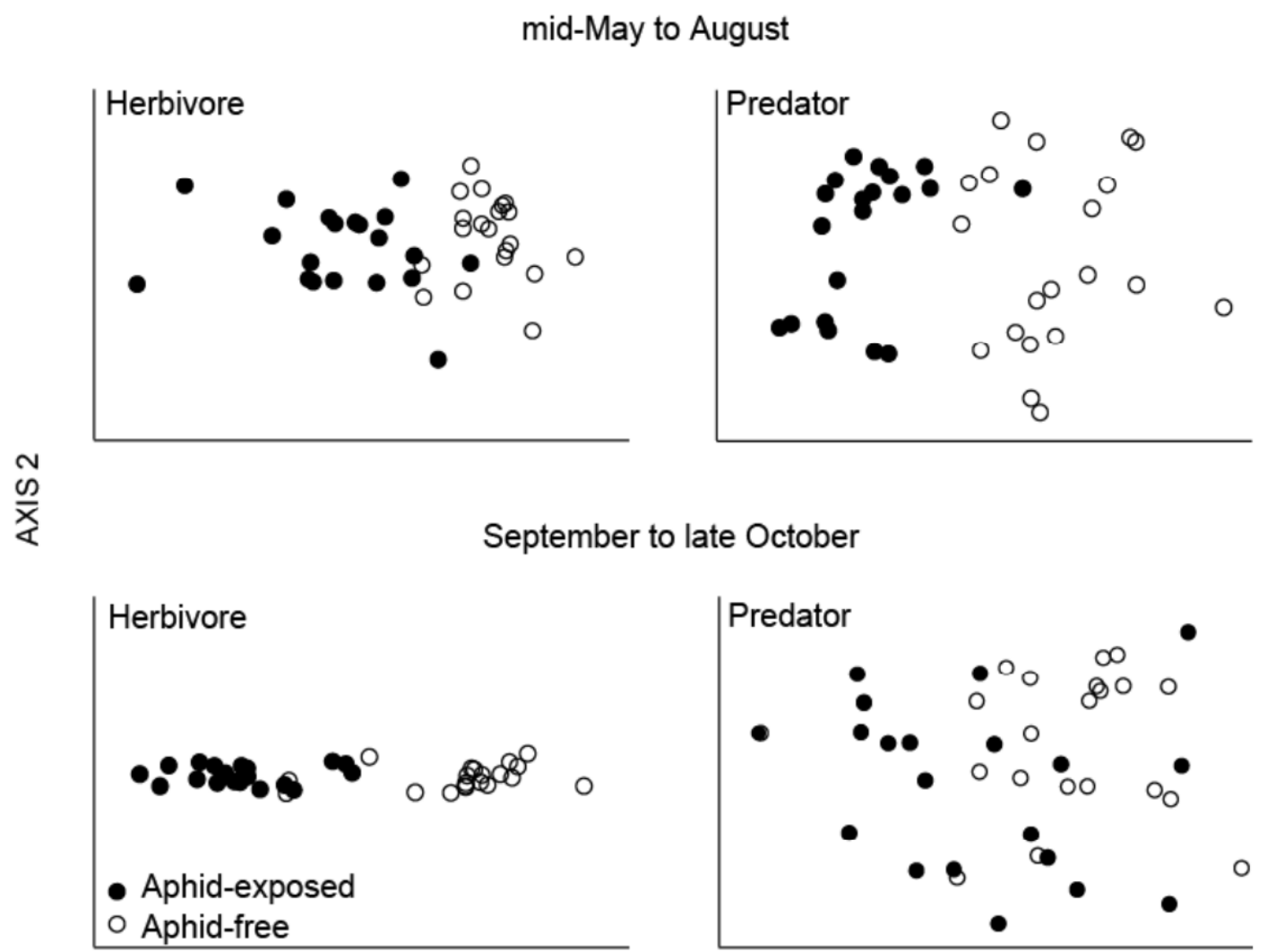

AXIS 1 
$1 \quad$ Fig. 3

Ando et al. 30

2

mid-May to August

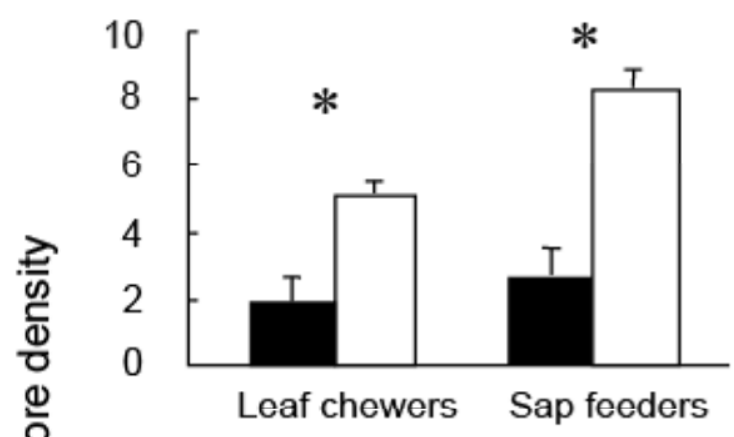

ํㅡㄴ

September to late August

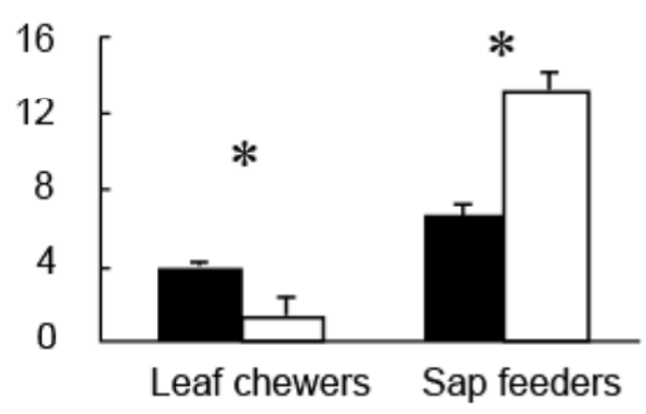

mid-May to August

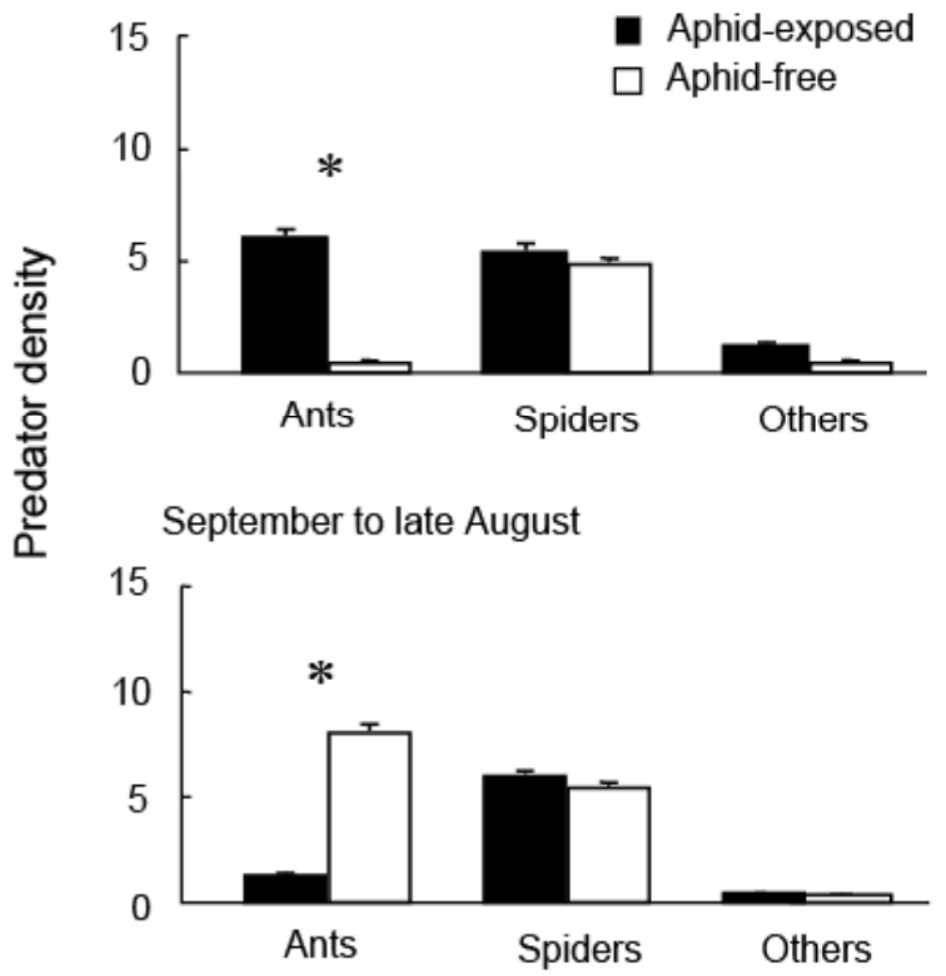


Ando et al. 31

1 Appendix 1. Herbivorous insects found on S. altissima.

\begin{tabular}{|c|c|c|c|c|c|c|}
\hline Species & $\begin{array}{c}\text { Feeding } \\
\text { guild }^{\mathrm{a}}\end{array}$ & $\begin{array}{l}\text { Host-plant } \\
\text { specificity }\end{array}$ & Stage & Season & $\begin{array}{l}\text { Aphid- } \\
\text { exposed }\end{array}$ & $\begin{array}{l}\text { Aphid- } \\
\text { free }\end{array}$ \\
\hline \multicolumn{7}{|l|}{ Coleoptera } \\
\hline \multicolumn{7}{|l|}{ Cerambycidae } \\
\hline Cerambycidae spec. 1 & LC & poly & adult & early & $\mathrm{Y}$ & $\mathrm{Y}$ \\
\hline \multicolumn{7}{|l|}{ Chrysomelidae } \\
\hline Aulacophora femoralis & LC & poly & adult & early & $\mathrm{Y}$ & $\mathrm{Y}$ \\
\hline Chrysolina aurichalcea & LC & oligo & adult & early & $\mathrm{Y}$ & $\mathrm{Y}$ \\
\hline Chrysomelidae spec. 1 & LC & poly & adult & early & $\mathrm{Y}$ & $\mathrm{Y}$ \\
\hline \multicolumn{7}{|l|}{ Scarabaeidae } \\
\hline Scarabaeidae spec. 1 & LC & poly & adult & both & $\mathrm{Y}$ & $\mathrm{Y}$ \\
\hline \multicolumn{7}{|l|}{ Diptera } \\
\hline \multicolumn{7}{|l|}{ Agromyzidae } \\
\hline Agromyzidae spec. 1 & LM & $?$ & larva & early & $\mathrm{Y}$ & $\mathrm{Y}$ \\
\hline \multicolumn{7}{|l|}{ Hemiptera } \\
\hline \multicolumn{7}{|l|}{ Acanthosomatidae } \\
\hline Acanthosomatidae spec. 1 & S & poly & adult & late & $\mathrm{Y}$ & $\mathrm{Y}$ \\
\hline \multicolumn{7}{|l|}{ Aphididae } \\
\hline Uroleucon nigrotuberculatum & S & mono & nymph, adult & early & $\mathrm{Y}$ & $\mathrm{N}$ \\
\hline Macrosiphoniella yomogicola & S & oligo & nymph, adult & late & $\mathrm{Y}$ & $\mathrm{Y}$ \\
\hline Aphididae spec. 1 & S & poly & nymph, adult & late & $\mathrm{Y}$ & $\mathrm{Y}$ \\
\hline Aphididae spec. 2 & S & poly & nymph, adult & late & $\mathrm{Y}$ & $\mathrm{Y}$ \\
\hline Aphididae spec. 3 & S & poly & nymph, adult & late & $\mathrm{Y}$ & $\mathrm{N}$ \\
\hline Aphididae spec. 4 & S & poly & nymph, adult & late & $\mathrm{Y}$ & $\mathrm{Y}$ \\
\hline Aphididae spec. 5 & S & poly & nymph, adult & late & $\mathrm{N}$ & $\mathrm{Y}$ \\
\hline Aphididae spec. 6 & S & poly & nymph, adult & late & $\mathrm{Y}$ & $\mathrm{Y}$ \\
\hline \multicolumn{7}{|l|}{ Coccidae } \\
\hline Parasaissetia nigra & S & poly & nymph, adult & late & $\mathrm{Y}$ & Y \\
\hline Coccidae spec. 1 & S & poly & nymph, adult & late & $\mathrm{Y}$ & $\mathrm{Y}$ \\
\hline \multicolumn{7}{|l|}{ Cercopidae } \\
\hline Aphrophora maritima & S & poly & adult & late & $\mathrm{Y}$ & $\mathrm{Y}$ \\
\hline \multicolumn{7}{|l|}{ Deltocephalidae } \\
\hline Nephotettix cincticeps & $S$ & poly & subadult & early & $\mathrm{Y}$ & $\mathrm{Y}$ \\
\hline \multicolumn{7}{|l|}{ Lygaeidae } \\
\hline Lygaeidae spec. 1 & S & poly & adult & early & $\mathrm{Y}$ & $\mathrm{Y}$ \\
\hline \multicolumn{7}{|l|}{ Plataspidae } \\
\hline Megacopta punctatissimum & S & poly & adult & early & $\mathrm{Y}$ & $\mathrm{Y}$ \\
\hline \multicolumn{7}{|l|}{ Tettigellidae } \\
\hline Bothrogonia ferruginea & S & poly & subadult & early & $\mathrm{Y}$ & $\mathrm{Y}$ \\
\hline Cicadella viridis & S & poly & subadult & early & $\mathrm{Y}$ & $\mathrm{Y}$ \\
\hline \multicolumn{7}{|l|}{ Lepidoptera } \\
\hline \multicolumn{7}{|l|}{ Geometridae } \\
\hline Ascotis selenaria & LC & oligo & larva & early & $\mathrm{Y}$ & $\mathrm{Y}$ \\
\hline Geometridae spec. 1 & LC & poly & larva & early & $\mathrm{Y}$ & $\mathrm{Y}$ \\
\hline Geometridae spec. 2 & LC & ? & larva & early & $\mathrm{Y}$ & $\mathrm{N}$ \\
\hline Geometridae spec. 3 & LC & ? & larva & early & $\mathrm{Y}$ & $\mathrm{Y}$ \\
\hline \multicolumn{7}{|l|}{ Orthoptera } \\
\hline \multicolumn{7}{|l|}{ Pyrgomorphidae } \\
\hline Atractomorpha lata & LC & poly & nymph, adult & late & $\mathrm{Y}$ & $\mathrm{Y}$ \\
\hline \multicolumn{7}{|l|}{ Tettigoniidae } \\
\hline Phaneroptera falcata & $\mathrm{LC}$ & poly & nymph, adult & late & $\mathrm{Y}$ & $\mathrm{Y}$ \\
\hline
\end{tabular}

$2 \mathrm{Y}=$ present, $\mathrm{N}=$ absent. 
Ando et al. 32

$1 \quad{ }^{\text {a }}$ LC $=$ leaf chewer, $\mathrm{LM}=$ leaf miner, $\mathrm{S}=$ sap feeder. $^{\mathrm{b}}$ mono $=$ monophagous (feeds on

2 the genus Solidago), oligo = oligophagous (feeds on Composites), poly = polyphagous

3 (feeds on several families). ${ }^{\mathrm{c}}$ both $=$ early and late seasons.

4 
Ando et al. 33

1 Appendix 2. Predators found on S. altissima.

\begin{tabular}{|c|c|c|c|c|c|}
\hline Species & Таха & Stage & Season & $\begin{array}{l}\text { Aphid- } \\
\text { exposed }\end{array}$ & Aphid-free \\
\hline \multicolumn{6}{|l|}{ Araneae } \\
\hline \multicolumn{6}{|l|}{ Argiopidae } \\
\hline Oxyopes sertatus & spider & nymph, adult & early / late & $\mathrm{Y}$ & $\mathrm{Y}$ \\
\hline \multicolumn{6}{|l|}{ Salticidae } \\
\hline \multirow[t]{2}{*}{ Salticidae spec. 1-spec. 25} & spider & nymph, adult & early / late & Y: spec. 1-22 & Y: spec. 1-20, 22-25 \\
\hline & & & & $\mathrm{N}$ : spec. $23-25$ & $\mathrm{~N}$ : spec. 21 \\
\hline \multicolumn{6}{|l|}{ Thomisidae } \\
\hline Misumenops tricuspidatus & spider & nymph, adult & early / late & $\mathrm{Y}$ & $\mathrm{Y}$ \\
\hline unidentified spider spec. 1- 25 & spider & adult & early / late & $\mathrm{Y}$ & $\mathrm{Y}$ \\
\hline \multicolumn{6}{|l|}{ Coleoptera } \\
\hline \multicolumn{6}{|l|}{ Cantharidae } \\
\hline Athemellus adusticollis & other & adult & early & $\mathrm{Y}$ & $\mathrm{Y}$ \\
\hline \multicolumn{6}{|l|}{ Coccinellidae } \\
\hline Coccinella septempunctata & other & larva, adult & early & $\mathrm{Y}$ & $\mathrm{Y}$ \\
\hline Harmonia axyridis & other & larva, adult & early & $\mathrm{Y}$ & $\mathrm{Y}$ \\
\hline Propylea japonica & other & adult & early & $\mathrm{N}$ & Y \\
\hline Unidentified spec. 1 & other & adult & early & $\mathrm{N}$ & $\mathrm{Y}$ \\
\hline \multicolumn{6}{|l|}{ Hemiptera } \\
\hline \multicolumn{6}{|l|}{ Reduviidae } \\
\hline Ectrychotes andreae & other & adult & early / late & $\mathrm{Y}$ & $\mathrm{Y}$ \\
\hline Sphedanolestes impressicollis & other & adult & early / late & $\mathrm{Y}$ & $\mathrm{Y}$ \\
\hline \multicolumn{6}{|l|}{ Hymenoptera } \\
\hline \multicolumn{6}{|l|}{ Formicidae } \\
\hline Camponotus japonicus & ant & adult & early / late & $\mathrm{Y}$ & $\mathrm{Y}$ \\
\hline Formica japonica & ant & adult & early / late & $\mathrm{Y}$ & $\mathrm{Y}$ \\
\hline Pristomyrmex pungens & ant & adult & early / late & $\mathrm{Y}$ & Y \\
\hline
\end{tabular}

2

$3 \quad \mathrm{Y}=$ present, $\mathrm{N}=$ absent. 